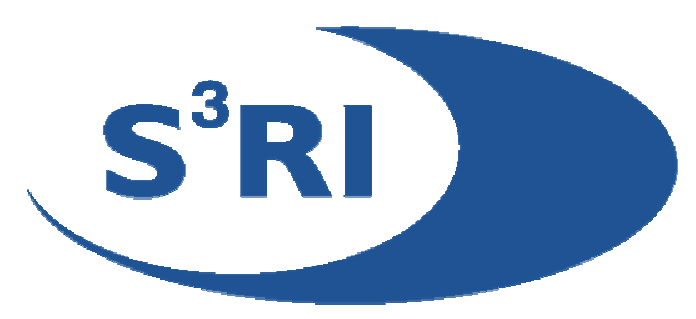

\title{
Demographic decomposition of the marriage market in England and Wales 1911-1991
}

\section{Máire Ní Bhrolcháin}

\begin{abstract}
A method for decomposing partner availability into its demographic components (preferences, previous birth trends, migration and mortality, and structure by marital status) is presented and applied to marriage market estimates for selected census years 1911-1991 in England and Wales. Preferences are the primary determinant of partner supply, but striking exceptions occur. Contrary to widespread assumption, variation in cohort sizes resulting from past fertility trends makes the smallest contribution to partner availability. Mortality and migration are next in order and the two marital status components are generally the largest in size. Determinants of intercensal change are similar to the cross-sectional picture.
\end{abstract}

\section{$S^{3}$ RI Applications Working Paper A04/06}




\title{
Demographic decomposition of the marriage market \\ in England and Wales 1911-1991*
}

\author{
Máire Ní Bhrolcháin \\ Division of Social Statistics \\ School of Social Sciences \\ University of Southampton \\ Southampton SO17 1BJ \\ email: mnb@socsci.soton.ac.uk
}

*My thanks to Wendy Sigle-Rushton who wrote the program to calculate the availability indices on which this paper is based. Our joint work on other aspects of these data is presented elsewhere. I am grateful also to the Office for National Statistics for supplying population estimates and to Dateline for providing age preference data. 


\begin{abstract}
A method for decomposing partner availability into its demographic components (preferences, previous birth trends, migration and mortality, and structure by marital status) is presented and applied to marriage market estimates for selected census years 1911-1991 in England and Wales. Preferences are the primary determinant of partner supply, but striking exceptions occur. Contrary to widespread assumption, variation in cohort sizes resulting from past fertility trends makes the smallest contribution to partner availability. Mortality and migration are next in order and the two marital status components are generally the largest in size. Determinants of intercensal change are similar to the cross-sectional picture.
\end{abstract}


This paper presents a method that decomposes measures of the marriage market - average partner availability by age and sex - into their demographic components and illustrates the method by applying it to England and Wales. The marriage market can be thought of in a narrower or broader sense - either in pure demographic terms, with age as the sole matching criterion, or in a broader sense, with matching not only on age but also on social and economic characteristics. The present paper measures partner availability in pure demographic terms - via numbers by age and sex, in combination with age preferences. This choice follows Dixon's (1978) classification of factors influencing the level and timing of marriage: the feasibility and attractiveness of marriage and the availability of partners. It is useful to distinguish and measure potential marriage opportunities and constraints that result purely from demographic conditions from any that may be superimposed on these by economic conditions or by social customs such as assortative mating and endogamy. Marriage rates have long been known to be linked to economic prosperity (Yule 1906; Glass 1938; Galbraith and Thomas 1941; Oppenheimer 1994, 2000) and so marriageability in economic terms - whether a person is employed or has satisfactory income and prospects - will in many cases reflect transient local or national economic conditions. It seems more appropriate that any constraints on or opportunities for marriage that result form economic and social factors should be identified separately from those due to demographic structure. A second reason for the choice is that although age preference data are available, no solid information exists on preferences for such partner attributes as educational level, social class and religion, and especially on how flexible these are. Goldman, Westoff and Hammerslough (1984) show that the precise matching rule adopted in relation to educational attainment strongly influences the resulting availability indicators and so, in the absence of explicit data on preferences for potential partners' social characteristics estimates of partner supply would be heavily influenced by the assumptions made. 


\section{MEASUREMENT AND DATA}

\section{Iterated Availability Ratio}

Partner supply is measured in this study by means of a weighted version of Lampard's (1993) Iterated Availability Ratio (IAR), a development of the Availability Ratio originally proposed by Goldman et al (1984). It measures the average number of potential partners available by age, taking account of age suitability and the competition within each sex for partners of the opposite sex. A particularly advantageous feature of the IAR is that, unlike the Goldman et al. measure, it sums to the total number of unmarried persons of each sex, in the age range covered. Preference data described in a later section are used to calculate the proportions, $\alpha_{\mathrm{ij}}$, of women of age $i$ who would accept a man aged $j$, and the corresponding proportions, $\beta_{\mathrm{ji}}$, of men aged $j$ who would accept a woman aged $i$. The product of these, $\lambda_{\mathrm{ij}}$, representing the joint preference of women aged $i$ and men aged $j$, is used as a set of age suitability weights in calculating the IAR. The IAR for woman $i$ is, then, the iterative solution to:

$$
I A R_{i}=\sum_{j} \frac{\lambda_{i j} / I A R_{i}}{\sum_{k} \lambda_{k j} / I A R_{k}}
$$

where the outermost summation extends over all males in the marriage market, and the summation in the denominator term extends over all women participants. The male IAR is specified correspondingly. The age range for each sex is 17-60.

\section{Age-Sex Distributions}

Age-sex distributions by marital status and single year of age were obtained from the England and Wales decennial censuses of 1911-1981, with the exception of 1941 when there was no census. Mid-year population estimates for England and Wales 1991 were used in preference to census data because of a sizeable undercount at ages 15-35 that was substantially larger among men than women (Heady, Smith and Avery 1994). At earlier censuses, the count was 
relatively accurate, and so no adjustments have been applied. Estimates of partner supply are obtained for the unmarried only but the effect of cohabitation has been examined; estimated availability ratios are fairly insensitive to the specification of availables as the unmarried who are not in a cohabiting partnership compared with the unmarried.

\section{Annual Births}

Annual totals of births for the years 1841-1974 are used in the decomposition and were obtained from Table 3.1 of OPCS (1987). The sex ratio at birth was assumed throughout to be 1.05.

\section{Age Preferences}

Any estimate of the relative numbers of men and women available for marriage must, for realism, incorporate an allowance for age preferences. It has long been known that the pairing of ages in marriage is not random but displays a preference for matches in which the groom is somewhat older than the bride, with the average gap being fairly narrow in England and Wales and in other West European countries. Previous studies of the marriage market in the aggregate have had to rely on assumption for the preference component of their marriage market estimates. Assumptions range from an arbitrary fixed preference of 2 or 3 years, to paired age ranges derived by a variety of methods based on observed marriages (Akers 1967; Hirschman and Matras 1971; Goldman et al. 1984; Henry 1969; Muhsam 1974; Schoen 1983). All of the assumptions and procedures adopted hitherto are known to be problematic and are usually acknowledged to be so. Assuming a fixed gap of 2 or 3 years in favour of the groom is unrealistic both because age differences vary considerably by age at marriage and because the variance in age differences is substantial (Goldman et al 1984; Casterline, Williams and McDonald 1988; Oppenheimer 1988). Furthermore, the majority of marriages do not feature age gaps of 2 or 3 years: in birth cohorts marrying between 1921 and 1988 in England and Wales the proportion of marriages in which the groom was 2 or 3 years older 
than the bride was below 50\% (Ní Bhrolcháin 2001). Deriving age preferences from the age differences observed in marriages occurring in a particular year or period is known to be an unsatisfactory solution because these result from a mixture of preferences and the opportunities (i.e. age-sex structure) available at a particular time (see e.g. Goldman et al 1984; Hirschman and Matras 1971; Schoen 1977 ). In the approach adopted by Qian and Preston (1993) age preferences do not need to be specified explicitly.

For these reasons, direct evidence on age preferences is highly desirable and can be expected to improve our knowledge in this area. Ideally, age preferences from a general population sample are required but to date preference information from a representative sample sufficiently large to be usable for demographic purposes has not been available, though explicit age preference information has been collected for small specialised samples of e.g. students and newspaper advertisers (see Buss 1994, Kenrick and Keefe 1992). The present study uses data obtained from a UK dating agency on the partner age preferences of 32,326 clients aged 18-60+ in 1996. Clients were asked to state the minimum and maximum age of partner that they would be prepared to accept. From these data, the proportions of men and women were obtained by single year of age 18-59 and 60+ who would accept a partner of each single year of age 18-59 and 60+. These were used as weights in calculating the iterated availability ratio. Age preference data were available only for ages $18-60+$ but since some men specified 17 as an acceptable partner age, weights were attributed to 17-year olds of each sex by setting them equal to those of 18 -years olds, lagged by one year of age. The preference data were top-coded at age 60 and so single year of age preferences are lacking at ages over 59. Experimental assignment of preferences to ages $60-70$ showed that availability ratios at ages 50-60 that were based on preferences and populations truncated at 60 were heavily biased, particularly for women. The preferences were therefore extended forward by 
attributing preferences to ages 60-70. Since the structure of age preferences, specific by age difference, was very similar in the age-range 50-59, the average preference at these ages for age differences in the range -41 to +10 years was assigned to ages and partner ages $60-70$. Preferences for age differences of 11-15 years were assigned by averaging the preferences of those aged 45-49, setting any unobserved preferences for age differences of 16 and above and below -41 to zero. The attribution of preferences affects largely the age group $50+$, and so their availability ratios are rather less firmly grounded than are those at younger ages. Further details together with a contour plot of the joint preference weights are given in Ní Bhrolcháin and Sigle-Rushton (2003).

Since the dating agency clients are not a probability sample, their preferences cannot necessarily be considered representative of those of the general population of unmarrieds. But since there is no external source against which they can be evaluated, validation of the preference information is, of necessity, indirect. Ní Bhrolcháin (2003) reports an extensive investigation of the dating agency preferences and establishes both (a) that the Dateline preferences can be considered reasonably representative of the preferences of the general British population in the 1990s and (b) that as preference weights they are superior to any available alternatives in making marriage market estimates throughout the twentieth century in Britain. The central points are as follows: (1) the age profile of mean age preferences corresponds well with the pattern of age differences by age of bride and by age of groom in recent decades in England and Wales, declining with the former and rising with the latter; (2) expected age differences based on the dating agency preferences provide a closer fit to observed age differences (evaluated by the root mean square error) than either fixed preferences of 2 or 3 years across the age range or preferences derived from observed age differences at each date by the method devised by Goldman et al (1984); in most comparisons 
at census dates from 1921-1991 (the comparison could not be carried out for 1911) (3)

relative gender differentials in the iterated availability ratio, to which the age preferences are a key input, correspond fairly well with gender differentials in marriage rates by age at census dates 1911-1991, though the correspondence is less good in 1961 and 1971; and (4) some features of the comparative preferences of men and women reproduce the findings of a general population survey of French couples carried out in 1984 (Ní Bhrolcháin 2001). The dating agency preferences are, in sum, the most realistic currently available for England and Wales. Since the objective of the present paper is to present a method of decomposition that is all that is required. The method can be applied with any set of preference data and does not rely on those used here.

Age preferences are assumed in this paper to be constant through time as in previous studies of time trends in the marriage market over shorter or longer periods (Akers 1967; Goldman et al 1984; Heer and Grossbard-Schechtman 1981; Henry 1969; Hirschman and Matras 1971; Schoen 1983). Detailed evidence supporting the assumption is set out elsewhere. The key points are these: (1) if preferences varied substantially through time, we would expect observed age differences to do so also; however, the mean age difference fluctuated within a fairly narrow range in England and Wales through the $20^{\text {th }}$ century; (2) if preferences were changing through the twentieth century, it is likely that there would have been a unidirectional trend towards e.g. smaller age differences reflecting more companionate marriages; however, the time series of mean age differences in England and Wales displays no secular trend rather it fluctuates and the fluctuations appear to be associated largely with the age structure of available partners (Ní Bhrolcháin 2001); (3) expected age differences earlier in the century can be predicted reasonably well from age structure together with the 1996 dating agency preferences; (4) in 1911, the start of the period analysed here, the profile by age of relative 
gender differentials in the IAR, which has preferences as a key input, is similar to that of gender differentials in marriage rates though the agreement in the absolute level of these two measures is not as close as later in the century. To assume constant preferences does not, of course, imply that the pattern of age matching in marriages has been constant through time. Observed matching patterns may alter in response to the age distribution of potential partner supply, but such changes need not entail a change in preferences.

\section{METHOD}

The method described here separates the Iterated Availability Ratio into its demographic components. The IAR has two inputs: the age preference weights and the age-sex distribution of the unmarried. The age-sex distribution of the unmarried at a point in time is, in turn, a function of past trends in birth numbers together with cumulative sex differentials in previous mortality, in net migration, and in the proportions unmarried, with the last three components being specific by age. The contribution of these components to the IAR can be quantified, with the mortality and net migration components being obtained jointly as a residual because neither detailed cohort survival nor cumulative net migration information by single year of age and sex is available for the relevant dates.

The method proceeds by calculating age and sex specific IARs for a number of population bases, and estimating the various components by subtraction. In what follows, subscripts for age and sex are omitted for clarity, and are implicit throughout. Let $\mathrm{IAR}_{\mathrm{u}}$ be the IAR for the unmarried (the overall IAR) and $\mathrm{IAR}_{\mathrm{r}}$ be the IAR for a rectangular population having equal numbers of men and women in each age group, then $\mathrm{IAR}_{\mathrm{r}}$ is the component of the overall IAR $\left(I_{A R}\right)$ that is attributable purely to age preferences, and the difference, $I_{A R}-I_{u} R_{r}$ is the total effect of all aspects of population structure on the availability ratios. The IAR estimated for people of all marital statuses, $\mathrm{IAR}_{\mathrm{a}}$, allows the overall effect of population structure (IAR 
- $\left.I A R_{r}\right)$ to be separated into a component due to age-sex structure $\left(\mathrm{IAR}_{\mathrm{a}}-\mathrm{IAR}_{\mathrm{r}}\right)$ and one due to structure by marital status $\left(\mathrm{IAR}_{\mathrm{u}}-\mathrm{IAR}_{\mathrm{a}}\right)$. Further components are obtained by calculating IARs for a population with a rectangular age structure but 1.05 men per woman in each age group ( $\mathrm{IAR}_{\mathrm{rsr}}$ ), a population comprising at each age $x$ in census year $t$ the number of births occurring in year $t-x$ distributed by sex by assuming a sex ratio at birth of 1.05 (IAR $)$, and finally the population of those never married $\left(\mathrm{IAR}_{\mathrm{n}}\right)$. The details are set out in Table 1 . The component due to fertility is separated into that attributable to the sex ratio at birth, and one due to trends in birth numbers per se. Note that the effect for marital structure reflects mortality to some degree, in that at older ages the higher proportions of women than men widowed are a sizeable element of this component. Apart from higher male mortality, two further factors contribute to the higher proportion of women than men widowed: the higher remarriage rates of previously married men $^{1}$ and the tendency for women to marry on average a somewhat older man. With an average age difference of around 3 years, the (former) husband of a married woman of a given age will be six years older on average than the (former) wife of a man of the same age: hence the greater risk of widowhood of a married woman of a given age compared with a married man of the same age comprises both the cumulative sex differential in mortality to that age and an average six additional years of cumulative sex differentials in mortality resulting from the disparities in their partners' ages.

\section{RESULTS}

\section{England and Wales 1911, 1951 and 1991}

While the decomposition has been applied to all census years 1911-1991, for economy the results are illustrated by three selected years, 1911, 1951 and 1991. The contribution of age

\footnotetext{
${ }^{1}$ For example, 1991 vital registration data for England and Wales show that the remarriage rate of previously married men was one third higher than that of women in the age-group 3544, 68\% higher at ages 45-54 and six times as high at ages 55+ (OPCS 1993, Table 3.3)
} 
preferences and of overall population structure to the age- and sex-specific iterated availability ratios for England and Wales for these years are shown in Figure 1 (the age preferences effect is, by assumption, constant through time). For women of all ages and for men under about 45 , the largest component by far is that due to age preferences. At male ages $45+$ at the two earlier dates the structural effect is close to or exceeds the effect of preferences. The structural effect is particularly strong for men in their 50s in 1951, the reasons for which will be discussed presently. Preferences are largely responsible for the age pattern of IARs at ages under about 40, after which structural factors are of increasing importance in generating the characteristic decline in female and improvement in male partner supply with rising age.

Figure 2 separates the overall structural effect into its components: birth trends (total effect including the sex ratio at birth), migration and mortality, and marital status (proportions never married and previously married). The effect of the sex ratio at birth (constant by assumption across all three dates) has not been plotted. It has, as would be expected, a small positive effect of 0.02-0.05 for women and ranges between -0.02 and -0.09 for men. The effect of the sex ratio at birth varies by age, since it interacts with the structure of age preferences which is not constant by age. We see that the total effect of births is small relative to other factors at these three dates, with, for women, a minimum value across these years of -0.04 and a maximum of 0.13 and for men a range of -0.12 to -0.002 . When the effect of the sex ratio at birth is omitted, thus confining the effect to the pure influence of time trends in fertility, these ranges are narrowed further to -0.06 to 0.05 (female) and -0.05 to 0.05 (male). Nevertheless, the fertility effect can, in some instances, be non-trivial, benefiting women by an additional 910 potential partners per 100 at ages under 43 in 1951, and by an additional 9-13 partners per 100 at ages 18-23 in 1991, with in each case a comparable deficit in male partner supply due 
to birth trends. But it is clear that the births component tends to be the smallest of all the structural components, a finding that contrasts sharply with the emphasis in the literature on fertility trends as a prime determinant of partner supply. Across all eight census years for which the decomposition has been carried out, the births component of female partner supply (including the sex ratio at birth) is the largest of the four age-specific structural components in absolute terms only in 1991, at ages under 29. Excluding the sex ratio at birth, this occurs only at ages 23 in 1981 and at ages 29-33 in 1991. Among men, fertility is of somewhat greater importance, with the overall births effect being the largest single structural component, in an absolute sense, at ages under 29 in 1991 and also at most ages under 24 in 1951 and 1971. Again, this effect owes much to the sex ratio at birth rather than reflecting fertility trends per se; excluding this, it features much less frequently. Birth trends are of greater importance, in relative terms, at younger than at older ages. Across the eight census years covered here, the births effect is never, age-specifically, the largest in absolute terms at ages over 33 .

The combined effects of mortality and migration are, as is seen in the second column of Figure 2, somewhat more substantial that the fertility component. The mortality and migration component declines across the century. This is what would be expected both from the decline in absolute sex differentials in mortality across the century, particularly at younger ages, and from the gradual elimination from the age-sex structure of the effects of the heavy excess male emigration in the late $19^{\text {th }}$ century and early decades of the $20^{\text {th }}$ century (Charlton 1997 , Carrier and Jeffery 1953, Dobson and McLaughlan 2001). In combination these sources accounted for a loss of between 15 and 23 potential partners per 100 women in 1911 compared with a range of -16 to +1 potential partners in 1991. Male marriage market gains from migration and mortality are in the range 5 to 31 per 100 in 1911 and 0 to 16 per 100 in 
1991. Male gains and female losses from this factor rise with age, as would be expected from cumulative sex differentials in mortality, and are particularly pronounced at the top of the age range considered in 1951, reflecting both war losses and excess male migration in the early decades of the century.

The effect of structure by marital status operates primarily through sex ratios by marital status. At a given date, these result essentially from the preceding history of age- and sexspecific marriage, marital dissolution and remarriage rates in interaction with overall age-sex structure. The third and fourth columns of Figure 2 show that both marital structure components can be very substantial indeed. Their impact can be particularly large at older ages, but may be sizeable at younger ages also. In 1911, the impact of sex differentials in the proportions single and sex ratios among the single results in a loss of between 3 and 21 potential partners per 100 for women in their 20s, and in gains of between 9 and 22 partners per 100 for men of this age. In 1951, non-marriage had a much smaller effect among the young, but had a very substantial effect indeed on partner supply at ages $45+$, particularly among men. It is this that explains most of the exceptionally large structural effect at older male ages in 1951. Sex ratios among the single from the early 40s were lower, and the excess female proportions single in the 40s and 50s higher in 1951 than at any of the three dates considered here. By 1991, the non-marriage component is mainly to women's advantage, and is very substantial at ages $40+$, with a correspondingly large disadvantage to older men. The effect of previous marriage on female partner supply was not very substantial in 1911 and 1951. Among men of 40+ it is somewhat larger in these years, adding between 3 and 21 potential partners per 100 men in 1911 and between 11 and 28 per 100 in 1951 . The previous marriage effect is much larger for both sexes in 1991, accounting for a shortfall of between 23 and 64 potential partners per 100 women aged 40+ and for gains of between 20 and 77 
potential partners per 100 men of this age. The reason for the substantially larger effect in 1991 is that the absolute differentials in sex ratios by marital status are much wider in 1991 than in the two earlier years. Sex ratios are certainly lower among the unmarried in earlier years than in 1991, but they do not differ as much from those of the single in 1911 and 1951 as they do in 1991. In 1991 the two marital status effects offset each other to some extent, but this is not true in earlier years.

The variation in each of the four structural components across all eight census years 1911 to 1991 is summarised in Figure 3. Figure 3a plots the minimum and maximum values of the births and mortality and migration components and Figure $3 b$ the corresponding values for the marital status components; for greater clarity, the scale of Figure $3 \mathrm{a}$ is four times as large as that of Figure 3b. Figure 3 underlines the findings presented thus far for the three selected

years. By comparison with other factors, fertility has not been a major component of partner supply for either sex in the period 1911-1991, and in size and range of variation it is eclipsed by the mortality and migration factor. Both of these components are well below the two marital status components in the size of their effects as well as in their range of variation, leaving aside the effect of previous marriage at the youngest ages which is negligible throughout.

\section{Intercensal Change}

Beyond the role of each demographic factor in determining partner supply at a point in time, the present section looks at how far each component contributes to change in partner availability through time. The proportionate contribution of each factor to change in male and female availability ratios by age is summarised in Table 2 for the period 1911-1991 and also for two sub-periods 1911-1951 and 1951-1991. The figures presented are unweighted averages across single years of age of the proportion of the overall change in the IAR that is 
accounted for by each factor. The average absolute change for each age group is given in italics in the top row of each bank of figures in Table 2. Note that where the proportion given for a factor is negative, the contribution of that factor is opposite in sign to the overall change. For example between 1911 and 1991 average supply at ages 35-49 declined by 0.53 potential partners per man, made up of an increase of $0.19(-0.53 \times-0.36)$ due to change in sex differentials in previous marriage, and declines of $0.02,0.13$ and 0.57 due to fertility, mortality + migration and non-marriage, respectively.

Availability ratios for women of all ages increased over the 80 years from 1911-1991, with the main improvement for women under 35 occurring by 1951 and that for older women between 1951 and 1991. The marriage market position of men deteriorated across the century, particularly at older ages. Again, change is not uniform across the entire period by age: most of the decline at younger ages occurred during the earlier part of the century and that at older ages in the more recent period. As would be expected from the findings presented in the preceding section, birth trends are not a major determinant of change in the marriage market over this period. Fertility accounts for no more than $30 \%$ of the average change in any female age group and for no more than $20 \%$ among males by age. This is true also of the two subperiods considered. Birth trends were responsible for no more than $28 \%$ of the improvement in the partner supply of women under 35 during 1911-1951 and for at most $36 \%$ of the decline in male partner supply at these ages. Fertility trends account for less than half of the change observed in 20 of the 24 age-sex groups set out in Table 2. In those cases where fertility is responsible for more than half of the change occurring, either the absolute change involved is small or the fertility effect is offset by other factors. 
A larger share of marriage market change during the 80 -year period is attributable to mortality and migration trends than to fertility. Between $34 \%$ and $55 \%$ of the improvement in women's marriage markets over the century was due to declining sex differentials in mortality and migration, with, correspondingly, a broadly similar role in the deterioration of male marriage markets. The impact of changing sex differentials in mortality and migration is most in evidence during the second half of the period. The mortality and migration experience in question is, of course, cumulative. Thus the increase between 1951 and 1991 of 0.11 (i.e. 0.31 $\mathrm{x} 0.34$ ) potential partners per woman aged $35-49$ that is due to mortality and migration is attributable to a reduction in the absolute size of sex differentials in mortality and migration from about 1891-1951 to 1941-1991 (Charlton, 1997; Carrier and Jeffery 1953).

In general, structure by marital status played a larger part in changing marriage markets than did age structure effects, particularly at ages 25+, over this period in England and Wales. A substantial part of the improvement in the marriage market position of women of all ages over the century is due to higher sex ratios among the single in 1991 than in 1911, though this improvement was offset to some extent by a deterioration due to the changing age-sex structure of the previously married. Essentially, sex ratios are more differentiated by marital status in 1991 than earlier in the century, with particularly high sex ratios among the single at ages $30+$.

\section{DISCUSSION}

Discussion of marriage market trends, and of the idea of marriage squeeze in particular, often assumes that trends in birth numbers are the key determinant of the cross-sectional state of the marriage market and of change in partner supply and so the results of the decomposition presented here are in some ways unexpected. The very modest size of the fertility effect is not due to restricted variability in birth numbers during the period covered. There is plenty of 
scope for a fertility effect to appear in the eighty year period covered, since it encompasses both long-run declines (early 1900s to 1930s) and rises (mid 1930s to mid 1960s) in annual birth numbers as well as sharp short-run fluctuations (1913-1927, 1941-1951) in births. In the light of these findings, the absence of evidence of either elevated marriage rates or of marriage squeeze among these cohorts, reported in an earlier paper, is unsurprising. That the fertility effect is not sizeable is partly explained by the smoothing across a range of adjacent ages that results from using the weighted availability ratio as a measure. Hence, effects on partner supply due to membership of, for example, the small cohorts of 1917-1919 and the large cohorts of 1920-21 are not perceptible in the fertility component for these cohorts in 1951. However, this does not explain the modest size of the fertility effect relative to other components, since all components are subject to the same smoothing process. The finding indicates that investigation of the possible impact of the relative numbers of the sexes on marriage rates, including marriage squeeze effects, would be more appropriately based on direct measures of partner supply by age rather than relying on relative cohort size as an indicator of demographic marriage market opportunities and constraints. Clearly the relative importance of fertility as a determinant depends on the contribution of the other components and it is noteworthy that its relative importance at younger ages was greater, particularly for men, later in the series considered here, when absolute sex differentials in mortality and migration had narrowed. Nevertheless, its significance in absolute terms is modest indeed.

The role of previous marriage, marital dissolution and remarriage patterns is often overlooked in commentary on marriage markets. Since the marriage market at a point in time consists of the relative numbers of the unmarried of each sex, previous trends in rates of marriage, remarriage, divorce and widow(er)hood, and sex differentials in these by age, can have a sizeable impact, and clearly have done so in England and Wales in the twentieth century. Part 
of the previous marriage effect reflects, as noted earlier, cumulative sex differentials in mortality beyond the age-range covered in the present study, though in 1991, the higher proportion of women than men currently divorced was a significant contributor to this component. The higher proportions of women previously married is also due in part to higher male remarriage rates and this in turn may be influenced by more advantageous supply conditions for older men. Hence, there may be an inflation/deflation effect in that better marriage markets for older men, and poorer ones for older women, may be self-reinforcing. 


\section{REFERENCES}

Akers, D.S. 1967. “On measuring the marriage squeeze.” Demography 4: 907-924.

Buss, D. 1994. The Evolution of Desire. New York: Basic Books

Carrier, N.H. and J.R. Jeffery. 1953. External Migration. (Studies on Medical and Population Subjects No. 6). London: HMSO.

Casterline, J.B., L. Williams, and P. McDonald. 1986. "The age difference between spouses: variations among developing countries", Population Studies 40: 353-374.

Charlton, J. 1997. "Trends in all-cause mortality: 1841-1994.” Chapter 3 in J. Charlton and M. Murphy (eds.) The Health of Adult Britain: 1841-1994, Vol. 1. London: The Stationery Office

Dixon, R. 1978. "Late marriage and non-marriage as demographic responses: are they similar?" Population Studies 32: 449-466.

Dobson, J. and G. McLaughlan. 2001. "International migration to and from the United Kingdom 1975-1999: consistency, change and implications for the labour market." Population Trends 106: 29-38.

Galbraith, V.L. and D.S. Thomas. 1941. "Birth rates and the interwar business cycles." Journal of the American Statistical Association 36: 465-476.

Glass, D. 1938. "Marriage frequency and economic fluctuations in England and Wales, 1851 to 1934.” pp 251-282 in Political Arithmetic, edited by L. Hogben. London: Allen and Unwin.

Goldman, N., C.F. Westoff and C. Hammerslough. 1984. "Demography of the marriage market in the United States." Population Index 50: 5-25.

Heady, P., S. Smith and V. Avery. 1994. 1991 Census Validation Survey: coverage report. London: HMSO 
Heer, D.M. and A. Grossbard-Schechtman. 1981. "The impact of the female marriage squeeze and the contraceptive revolution on sex roles and the women's liberation movement in the United States, 1960-1975.” Journal of Marriage and the Family 43: 49-65.

Henry, Louis. 1969. "Schémas de nuptialite: déséquilibre des sexes et age au mariage." Population 24: 1067-1122.

Hirschman, C. and J. Matras. 1971. "A new look at the marriage market and nuptiality rates, 1915-1958.” Demography 8: 549-569.

Kenrick, D. and R. Keefe. 1992. “Age preferences in mates reflect sex differences in reproductive strategies. Behavioral and Brain Sciences 15: 75-133.

Lampard, R. 1993. "Availability of marriage partners in England and Wales: a comparison of three measures." Journal of Biosocial Science 25: 333-350.

Muhsam, H.V. 1974. “The marriage squeeze.” Demography 11: 291-299.

Ní Bhrolcháin, M. 2001. "Flexibility in the marriage market.” Population - An English Selection 13(2): 9-48.

Ní Bhrolcháin, M. and Sigle-Rushton, W. 2003. "Gender contrasts in partner supply: marriage market estimates and their implications."

Ní Bhrolcháin, M. 2003. "Validating age preferences for marriage market analysis."

Office of Population Censuses and Surveys. 1987. Birth Statistics 1837-1983. Series FM1, No. 13. London: HMSO.

Office of Population Censuses and Surveys. 1993. Marriage and Divorce Statistics 1991. Series FM1 No. 19. London: HMSO.

Oppenheimer, V.K. 1994. "Women's rising employment and the future of the family in industrial societies.” Population and Development Review 20, 293-342. 
Oppenheimer, V.K. 2000. “The continuing importance of men's economic position in marriage formation.” Pp. 283-301 in The Ties That Bind. Perspectives on Marriage and Cohabitation, edited by L.J. Waite. New York: Aldine de Gruyter.

Qian, Z. and S. Preston. 1993. "Changes in American marriage, 1972 to 1987: availability and forces of attraction by age and education.” American Sociological Review 58: 482-495

Schoen, Robert. 1977. “A two-sex nuptiality-mortality life table”, Demography 14: 333-350.

Schoen, Robert. 1983. "Measuring the tightness of a marriage squeeze.” Demography 20: 61-78.

Yule, G. U. 1906. "On the changes in marriage- and birth-rates in England and Wales during the past half century; with an inquiry as to their probable causes." Journal of the Royal Statistical Society 69: 88-147. 
Table 1 Decomposition of the availability ratio for the unmarried: specification of components

Age preferences

Overall population structure

Age-sex structure

Sex ratio at birth

Birth trends

Mortality and migration

Structure by marital status

\section{Never married \\ Previously married}

IAR $_{\mathrm{r}}$

$\mathrm{IAR}_{\mathrm{u}}-\mathrm{IAR}_{\mathrm{r}}$

$\mathrm{IAR}_{\mathrm{a}}-\mathrm{IAR}_{\mathrm{r}}$

$\mathrm{IAR}_{\mathrm{rsr}}-\mathrm{IAR}_{\mathrm{r}}$

$\mathrm{IAR}_{\mathrm{b}}-\mathrm{IAR}_{\mathrm{rsr}}$

$\mathrm{IAR}_{\mathrm{a}}-\mathrm{IAR}_{\mathrm{b}}$

$\mathrm{IAR}_{\mathrm{u}}-\mathrm{IAR}_{\mathrm{a}}$

$\mathrm{IAR}_{\mathrm{n}}-\mathrm{IAR}_{\mathrm{a}}$

$\mathrm{IAR}_{\mathrm{u}}-\mathrm{IAR}_{\mathrm{n}}$

where the population base for each IAR is as follows:

$\mathrm{IAR}_{\mathrm{u}} \quad$ the unmarried

$\mathrm{IAR}_{\mathrm{a}} \quad$ all marital statuses

$\mathrm{IAR}_{\mathrm{n}} \quad$ the never married

$\mathrm{IAR}_{\mathrm{r}} \quad$ rectangular population with equal numbers of men and women at each age

IAR $_{\mathrm{rsr}} \quad$ rectangular population with 105 men per 100 women at each age

$\mathrm{IAR}_{\mathrm{b}} \quad$ the original birth cohorts of men and women of each age at each census year $\mathrm{t}$; that is men aged $\mathrm{x}=1.05 * \operatorname{Births}(\mathrm{t}-\mathrm{x}) / 2.05$ and women aged $\mathrm{x}=\operatorname{Births}(\mathrm{t}-$ $\mathrm{x}) / 2.05$ where Births $(\mathrm{t}-\mathrm{x})=$ births in the calendar year $\mathrm{t}-\mathrm{x}$. 
Table 2 Proportion of change in availability ratios attributable to each component, by sex and age group. England and Wales, 1911-1991, 1911-1951, 1951-1991.

\begin{tabular}{|c|c|c|c|c|c|c|c|c|}
\hline & \multicolumn{3}{|c|}{ Female } & \multicolumn{5}{|c|}{ Male } \\
\hline & $17-24$ & $25-34$ & $35-49$ & $50-60$ & $17-24$ & $25-34$ & $35-49$ & $50-60$ \\
\hline $\begin{array}{l}\text { 1911-1991 } \\
\text { Mean absolute change } \\
\text { Proportion accounted } \\
\text { for by: }\end{array}$ & 0.31 & 0.33 & 0.35 & 0.20 & -0.19 & -0.38 & -0.53 & -0.62 \\
\hline$\overline{\text { Births }}$ & 0.12 & -0.04 & 0.05 & 0.30 & 0.20 & -0.02 & 0.03 & 0.07 \\
\hline $\begin{array}{l}\text { Mortality and } \\
\text { migration }\end{array}$ & 0.55 & 0.43 & 0.34 & 0.51 & 0.50 & 0.43 & 0.25 & 0.24 \\
\hline Never married & 0.35 & 0.65 & 1.48 & 3.20 & 0.28 & 0.65 & 1.08 & 1.38 \\
\hline Previously married & -0.02 & -0.05 & -0.87 & -3.01 & 0.02 & -0.06 & -0.36 & -0.69 \\
\hline $\begin{array}{l}\text { 1911-1951 } \\
\text { Mean absolute change }{ }^{2} \\
\text { Proportion accounted } \\
\text { for by: }\end{array}$ & 0.22 & 0.22 & 0.04 & -0.12 & -0.12 & -0.35 & -0.08 & 0.53 \\
\hline Mortality and & 0.18 & 0.28 & 0.61 & -0.44 & 0.36 & 0.18 & -1.27 & -0.09 \\
\hline migration & 0.18 & 0.23 & 0.34 & 0.42 & 0.28 & 0.21 & -0.76 & 0.07 \\
\hline Never married & 0.68 & 0.69 & 0.45 & 0.89 & 0.38 & 0.72 & 1.55 & 0.90 \\
\hline Previously married & -0.04 & -0.20 & -0.40 & 0.13 & -0.02 & -0.11 & 1.48 & 0.12 \\
\hline $\begin{array}{l}\text { 1951-1991 } \\
\text { Mean absolute change } \\
\text { Proportion accounted } \\
\text { for by: }\end{array}$ & 0.09 & 0.11 & 0.31 & 0.32 & -0.06 & -0.03 & -0.45 & -1.15 \\
\hline Births & -0.03 & -0.67 & -0.22 & 0.01 & -0.15 & 13.28 & -0.15 & 0.00 \\
\hline $\begin{array}{l}\text { Mortality and } \\
\text { migration }\end{array}$ & 1.44 & 0.90 & 0.34 & 0.47 & 1.03 & -16.41 & 0.24 & 0.16 \\
\hline Never married & -0.45 & 0.50 & 1.61 & 2.28 & -0.02 & 7.95 & 1.17 & 1.15 \\
\hline Previously married & 0.04 & 0.26 & -0.72 & -1.76 & 0.13 & -3.82 & -0.25 & -0.32 \\
\hline
\end{tabular}

\footnotetext{
${ }^{2}$ Unweighted average of change in availability ratios at single years of age within each age group.
} 
Figure 1 Components of availability ratios due to preferences and to age-sex structure, by sex. England and Wales, 1911, 1951, 1991
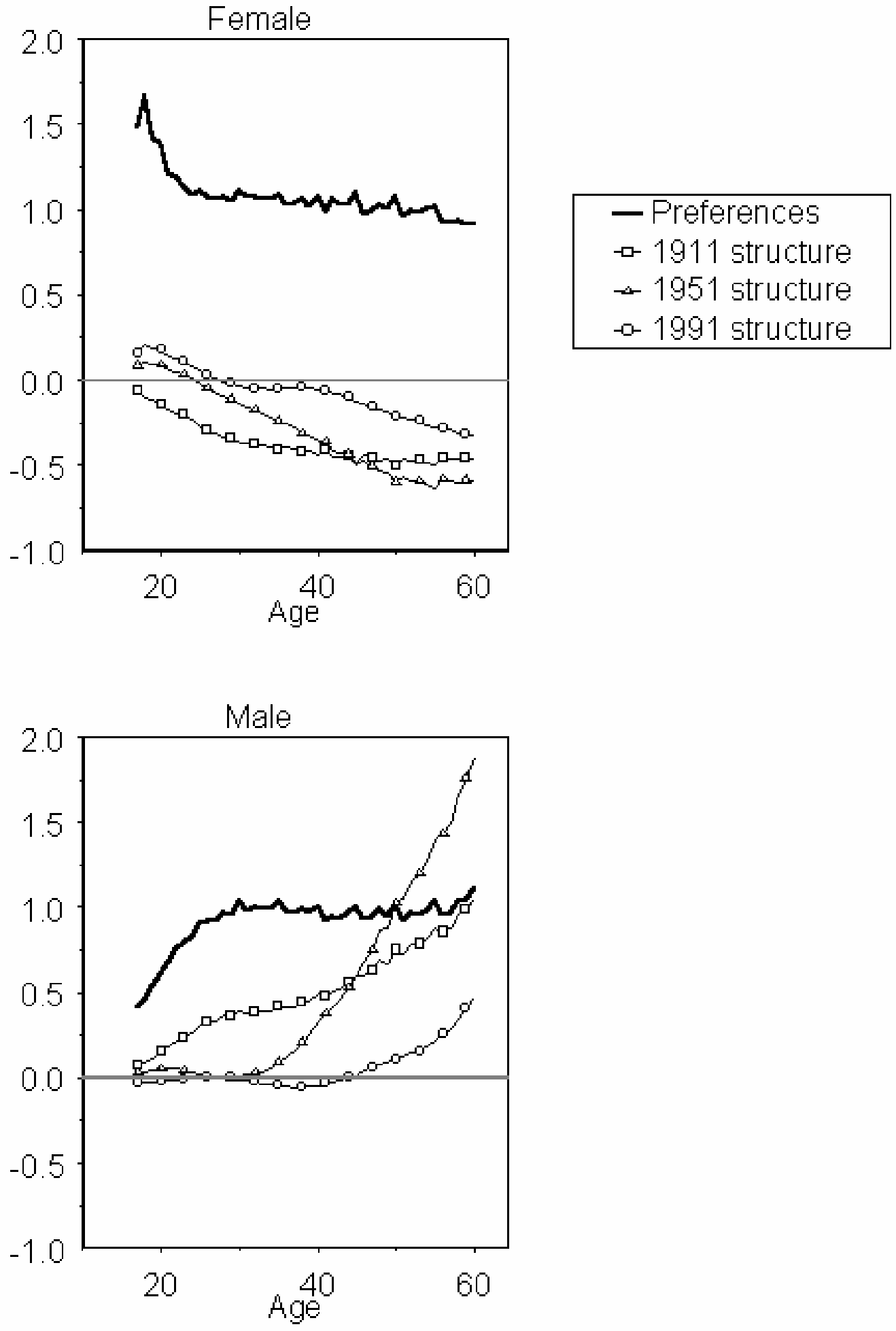
Figure 2. Components of availability ratio by age and sex, E+W 1911, 1951, 1991

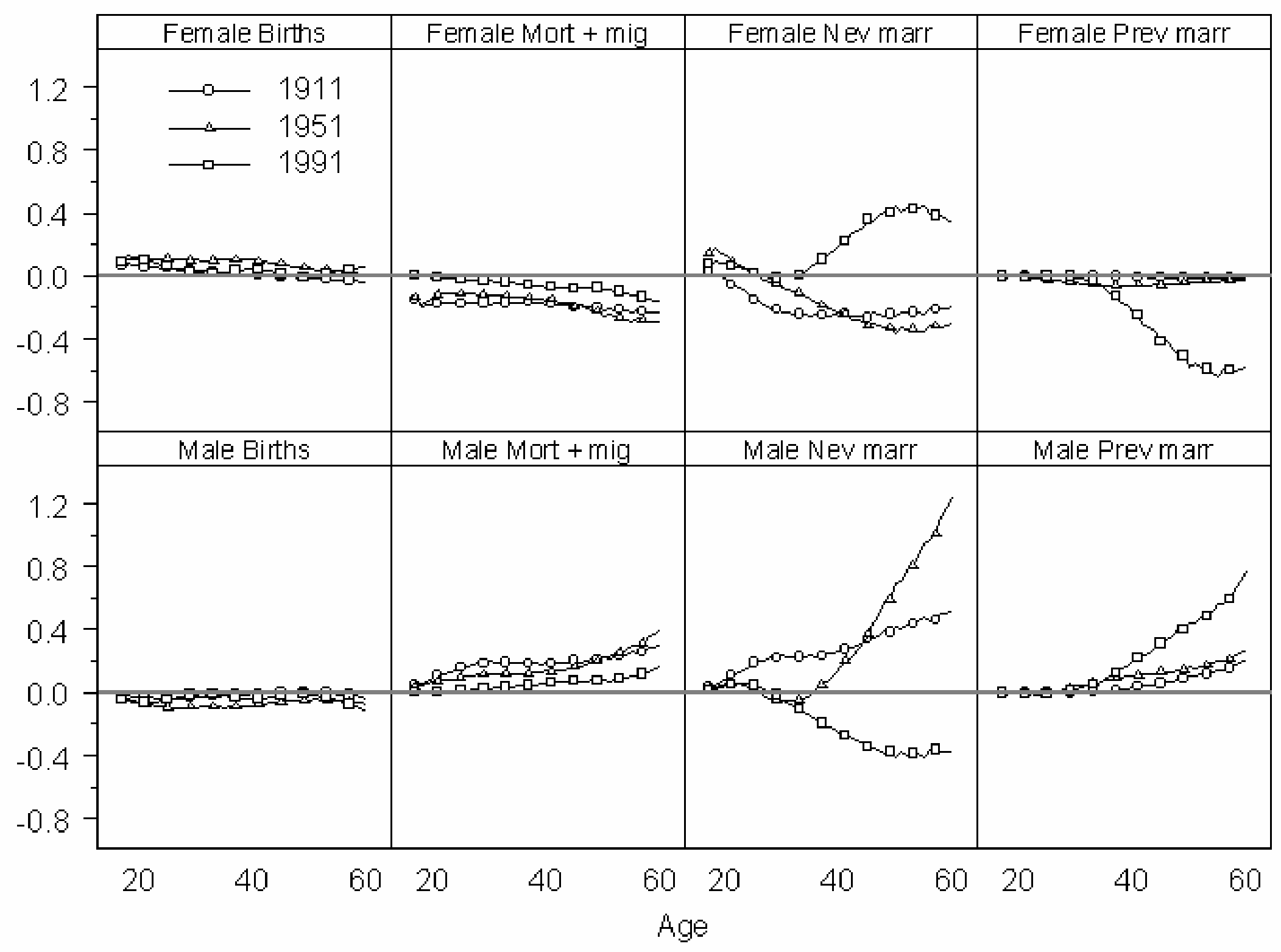


Figure 3a. Minimum and maximum values of age structure components, by sex, E+W 1911-1991

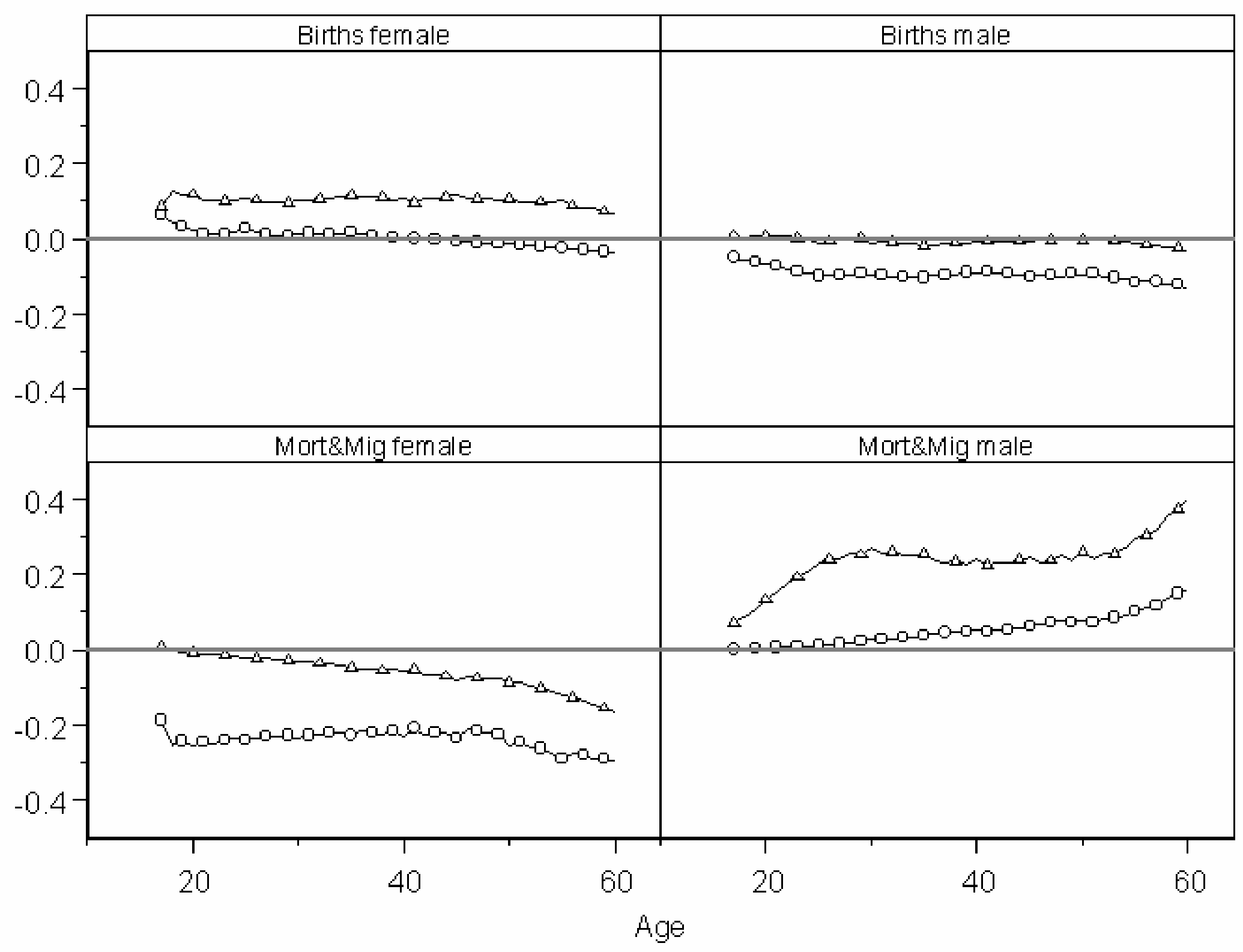


Figure 3b. Minimum and maximum values of marital status components, by sex, E+W 1911-1991

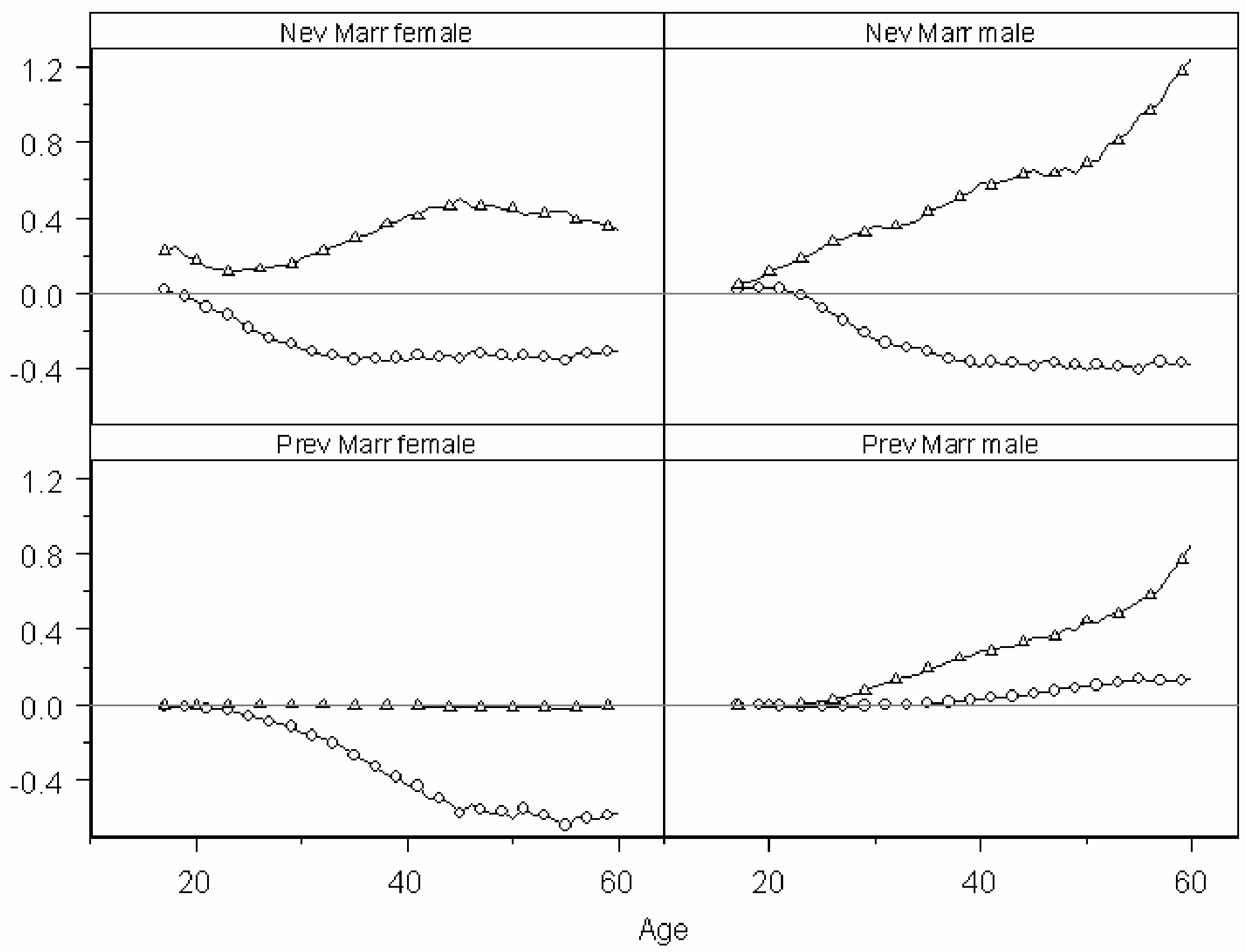

